\title{
True power loss reduction by mountain zebra, augmented bat, and improved kidney search algorithms
}

\author{
Lenin Kanagasabai \\ Department of Electrical and Electronic Engineering, Prasad V. Potluri Siddhartha Institute of Technology, India
}

\begin{tabular}{l} 
Article Info \\
\hline Article history: \\
Received Apr 29, 2021 \\
Revised May 31, 2021 \\
Accepted Jun 7, 2021 \\
\hline
\end{tabular}

Keywords:

Augmented bat Improved kidney search Mountain zebra Optimal reactive power Transmission loss

\begin{abstract}
In this paper optimal reactive power problem is solved by mountain zebra algorithm (MZA), augmented bat algorithm (AB), and improved kidney search (IKS) algorithm. In the proposed algorithm, an intermediate state has been established at first, and then explores the intermediate state in order to obtain the global optima. Iterative local search implemented in this proposed algorithm. This technique enhances the search procedure in rapid mode. Then in this work, IKS algorithm has been proposed for solving optimal reactive power problem. In initial phase, a random population of probable solutions is created and re-absorption, secretion, excretion are imitated in the search process to check various conditions entrenched to the algorithm. The algorithm has been built to advance the search even a potential solution moved to waste (W) and it will be brought back to the filtered blood (FB). Glomerular filtration rate (GFR) test is utilized to verify the fitness of kidneys. Better efficiency of the proposed MZA, AB, and IKS algorithm confirmed by successful evaluation in standard IEEE 14-bus, 118-bus, and 300-bus test systems. The results show that active power loss has been reduced.
\end{abstract}

This is an open access article under the $\underline{C C B Y-S A}$ license.

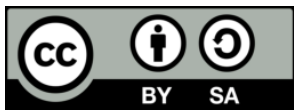

\section{Corresponding Author:}

Lenin Kanagasabai

Department of Electrical and Electronic Engineering

Prasad V. Potluri Siddhartha Institute of Technology

Kanuru, Vijayawada, Andhra Pradesh 520007, India

Email; gklenin@gmail.com

\section{INTRODUCTION}

To minimize the true power loss is key aim in this reactive power optimization problem. Various techniques [1]-[6] have been applied to solve the reactive power optimization problem. Yet many difficulties are found while solving problem due to various types of constraints. After that many evolutionary techniques [7]-[16] applied to solve the reactive power problem, but many algorithms stuck in local optimal solution also failed to balance the exploration and exploitation during the search of global solution. In this work mountain zebra algorithm (MZA), augmented bat algorithm (AB), and improved kidney search (IKS) algorithm is applied for solving reactive power optimization problem. MZA emulates the searching techniques of the mountain zebra behaviour. Mainly mountain zebra utilize its special logical, cooperative and self-determining approach in its search to find the grassland. This technique enhances the search procedure in rapid mode. Then this paper proposes $\mathrm{AB}$ algorithm to solve optimal reactive power problem. Bat algorithm is mimicked from the actions of the bat and it fly randomly to look for the prey. Wavelength can be adjusted regularly and can control the rate of pulse emission $r \in[0 ; 1]$, depend on the propinquity of the target. Standard bat algorithm often falls into the local optima when applied to many optimization problems. In the proposed $\mathrm{AB}$ algorithm local an intermediate state has been established at first, and then 
explore the intermediate state in order to obtain the global optima. In the proposed algorithm, balance between local and global search has been maintained. Movements of the bats by toggle between local search and global search is controlled by the pulse rate $\mathrm{r}$ and receipt or refusal of a new-fangled engendered solution is controlled by loudness A.

Then in this work, IKS algorithm is proposed to solve the optimal reactive power problem. It imitates assorted progression of a biological kidney. Four main activities: filtration, re-absorption, secretion, and excretion play major role in the operation of kidneys. Kidneys function plays major role in urine formation and blood filtration in the human body. Fundamentally, the kidneys supervise the quantity of ions in the blood and also decrease the presence of surplus water and waste. In initial phase, a random population of probable solutions is created and re-absorption, secretion, and excretion are imitated in the search process to check various conditions entrenched to the algorithm. The algorithm is built to improve the search even a potential solution moved to waste (W) and it will be brought back to the filtered blood (FB). Glomerular filtration rate (GFR) test is utilized to verify the fitness of kidneys. Proposed MZA, AB, and IKS algorithm efficiency is verified by testing it in standard IEEE 14-bus, 118-bus, and 300-bus test systems.

\section{OBJECTIVE FUNCTION}

Objective of the problem is to reduce the true power loss as (1).

$$
\mathrm{F}=\mathrm{P}_{\mathrm{L}}=\sum_{\mathrm{k} \in \mathrm{Nbr}} \mathrm{g}_{\mathrm{k}}\left(\mathrm{V}_{\mathrm{i}}^{2}+\mathrm{V}_{\mathrm{j}}^{2}-2 \mathrm{~V}_{\mathrm{i}} \mathrm{V}_{\mathrm{j}} \cos \theta_{\mathrm{ij}}\right)
$$

Voltage deviation is given as (2).

$$
\mathrm{F}=\mathrm{P}_{\mathrm{L}}+\omega_{\mathrm{v}} \times \text { Voltage Deviation }
$$

Voltage deviation is given by (3).

$$
\text { Voltage Deviation }=\sum_{i=1}^{N p q}\left|V_{i}-1\right|
$$

In equality constraint is given by (4).

$$
P_{G}=P_{D}+P_{L}
$$

In inequality constraints are given by (5)-(9).

$$
\begin{aligned}
& \mathrm{P}_{\text {gslack }}^{\text {min }} \leq \mathrm{P}_{\text {gslack }} \leq \mathrm{P}_{\text {gslack }}^{\text {max }} \\
& \mathrm{Q}_{\mathrm{gi}}^{\text {min }} \leq \mathrm{Q}_{\mathrm{gi}} \leq \mathrm{Q}_{\mathrm{gi}}^{\text {max }}, \mathrm{i} \in \mathrm{N}_{\mathrm{g}} \\
& \mathrm{V}_{\mathrm{i}}^{\mathrm{min}} \leq \mathrm{V}_{\mathrm{i}} \leq \mathrm{V}_{\mathrm{i}}^{\text {max }}, \mathrm{i} \in \mathrm{N} \\
& \mathrm{T}_{\mathrm{i}}^{\mathrm{min}} \leq \mathrm{T}_{\mathrm{i}} \leq \mathrm{T}_{\mathrm{i}}^{\max }, \mathrm{i} \in \mathrm{N}_{\mathrm{T}} \\
& \mathrm{Q}_{\mathrm{c}}^{\min } \leq \mathrm{Q}_{\mathrm{c}} \leq \mathrm{Q}_{\mathrm{C}}^{\max }, \mathrm{i} \in \mathrm{N}_{\mathrm{C}}
\end{aligned}
$$

\section{MOUNTAIN ZEBRA ALGORITHM}

Natural behaviour of mountain zebra during the scavenging endeavors has been pretended in MZA. Mountain zebra search in group to find the food. Alike to plain zebras, mountain zebras do not be in cumulative into big herds. Only they compose as small family groups consisting of a solo stallion around one to five mares, jointly with their current offspring's. Single males reside in divided groups, and adult single try to confine young mares to set up a harem. In this they are divergent by the leading stallion of the group.

At a single time, mares give birth to one foal. For about a year, the foal feeds mainly on its mother's milk after which it is weaned onto hard search. Between the ages of 13 and 37 months mountain zebra foals commonly move away from their maternal herds for some time. Conversely Hartmann's mountain zebra mares force out their foals when they are aged around 14 to 16 months. For a while, young males may wander alone before joining a bachelor group, while females are either taken into another breeding herd or 
are joined by a single male to structure a novel breeding herd. Independent nature of mountain zebra is identified and integrated into the algorithm. It has been represented by (10).

$$
c_{k+1}=c_{k}+r_{g 1} a_{1}\left(l o_{\max }-d_{k}\right)+r_{g 2} a_{2}\left(l f_{\max }-d_{k}\right)
$$

Where $c_{k}, d_{k}$ represents the exploration and exploitation; $r_{g 1}, r_{g 2}$ are learning factors; $a_{1}, a_{2}$ are random numbers. To prominent (best) mountain zebra there will be an interface with numerous mountain zebra s (10), and comparison will be there with each mountain zebra. Movement to other locations is expressed by (11).

$$
\mathrm{d}_{\mathrm{k}+1}=\lambda\left(\mathrm{c}_{\mathrm{k}}+\mathrm{d}_{\mathrm{k}}\right)
$$

Each mountain zebra's fitness will be updated and both the $\mathrm{If}_{\max }$ (individual Mountain Zebra's location) and $\mathrm{lo}_{\max }$ (the Mountain Zebra's herd's best location) will be determined. When present fitness is superior then $\left(\mathrm{lf}_{\max }\right.$ ) location vector of particular mountain zebra is protected. Movement of mountain zebra $\mathrm{s}$ to stay or exploit within the exploration space and can be controlled by (10) and (11). On consideration of the two competing forces $\left(\mathrm{lo}_{\max }, \mathrm{lf}_{\max }\right)$ mountain zebra s move to search other areas through (11).

Dimensional element $d_{k}$ is subtracted from the maximum vector and multiplied by an arbitrary number $\left(\mathrm{a}_{1}, \mathrm{a}_{2}\right)$ (between 0.0 and 0.6 ) with learning parameter $\left(\mathrm{r}_{\mathrm{g} 1}, \mathrm{r}_{\mathrm{g} 2}\right)$. Movement is updated for global and local search by (12), (13).

$$
\begin{aligned}
& V_{l_{i, d}^{t+1}}^{t+}=V_{l_{i, d}^{t}}^{t+1} \omega^{t}+\operatorname{random}(1, d) \odot\left(F_{B e s t, d}^{t}-Y_{i, d}^{t}\right) \text { if random }>P[\text { for global search }] \\
& V_{l_{i, d}^{t+1}}^{t}=V_{l_{i, d}^{t+1}}^{t} \omega^{t}+\operatorname{random}(1, d) \odot\left(G_{B e s t, d}^{t}-Y_{i, d}^{t}\right) \text { if random } \leq P[\text { for local search }]
\end{aligned}
$$

Then the position is modified by (14).

$$
Y_{i, d}^{t+1}=V_{l, d}^{t+1}+y_{i, d}^{t}
$$

Worst fitness value separator will be implemented by (15).

$$
Y_{\text {worst }, l i}=Y_{\min }+\left(Y_{\max }-Y_{\min }+1\right) \times \text { random }
$$

MZA algorithm for solving reactive power problem

Step a: Reactive power problem objective function has been initiated in the process.

Step b: At random mountain zebra s are initiated in the solution space

Step c: Fitness values has been updated by (10)

Step d: Location of mountain zebra is modified by (11)

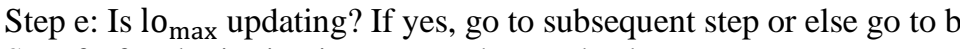

Step f: If end criterion is not met, then go back to step c

Step g: Optimized output

\section{AUGMENTED BAT ALGORITHM}

Bat algorithm is mimicked from the actions of the bat and it fly randomly to look for the prey. Wavelength can be adjusted regularly and can control the rate of pulse emission $r \in[0 ; 1]$, depend on the propinquity of the target [17]. Loudness is assumed to be varying from a large (positive) $A_{0}$ to minimum constant value $A_{\text {min }}$.

Fresh solutions are produced by (16)-(18).

$$
\begin{aligned}
& \mathrm{f}_{\mathrm{i}}^{(\mathrm{t})}=\mathrm{f}_{\min }+\left(\mathrm{f}_{\max }-\mathrm{f}_{\min }\right) \mathrm{u}(0,1) \\
& \mathrm{v}_{\mathrm{i}}^{(\mathrm{t}+1)}=\mathrm{v}_{\mathrm{i}}^{\mathrm{t}}+\left(\mathrm{x}_{\mathrm{i}}^{\mathrm{t}}-\text { best }\right) \mathrm{Q}_{\mathrm{i}}^{(\mathrm{t})}, \\
& \mathrm{x}_{\mathrm{i}}^{(\mathrm{t}+1)}=\mathrm{x}_{\mathrm{i}}^{(\mathrm{t})}+\mathrm{v}_{\mathrm{i}}^{(\mathrm{t})}
\end{aligned}
$$

For local search a capricious walk with direct exploitation is used to modernize the present most excellent solution by (19).

True power loss reduction by mountain zebra, augmented bat and improved kidney ... (Lenin Kanagasabai) 


$$
x^{(t)}=\text { best }+\epsilon A_{i}^{(t)}(2 U(0,1)-1)
$$

$\epsilon$ - scaling factor, $A_{i}^{(t)}$ - loudness. Depending on the pulse rate $r_{i}$ and new-fangled solutions are accepted with some proximity local search will be commenced. When bat finds a prey rate of pulse emission $\mathrm{r}_{\mathrm{i}}$ augments and loudness Ai diminished, which mathematically written by (20).

$$
A_{i}^{(t+1)}=\alpha A_{i}^{(t)}, r_{i}^{(t)}=r_{i}^{(0)}[1-\exp (-\gamma \epsilon)]
$$

Standard Bat algorithm often falls into the local optima when applied to many optimization problems [17]. In the proposed $\mathrm{AB}$ algorithm, an intermediate state is established at first, and then explore the intermediate state in order to obtain the global optima. Iterative local search implemented in this proposed algorithm as follows:

Step a. $X_{*}$ defines the best solution and is perturbed to attain an intermediate state $X_{* *}$ given by (21).

$$
X_{* *}=X_{*} \times \text { random }()
$$

Step b. Intermediate state $X_{* *}$ has been re-searched in order to get the local optimal solution $X_{*}^{\prime}$, the local optima $f\left(X_{*}^{\prime}\right)$.

Step c. When $f\left(X_{*}^{\prime}\right)<f\left(X_{*}\right)$, then $X_{*}^{\prime}=X_{*} f\left(X_{*}\right)=f\left(X_{*}^{\prime}\right)$ otherwise $x p\left(-\left(f\left(X_{*}^{\prime}\right)-f\left(X_{*}\right)\right)\right)>$ random ( ), then $X_{*}^{\prime}=X_{*} f\left(X_{*}\right)=f\left(X_{*}^{\prime}\right)$.

Step d. Output the most excellent solution.

Stochastic inertia weight (SIW) is applied in the proposed algorithm.

$$
\omega=\mu_{\min }+\left(\mu_{\max }-\mu_{\min }\right) \times \text { random }+\sigma \times \operatorname{randomn}()
$$

The velocity of the population updated by (23).

$$
V_{i}^{t}=\omega V_{i}^{t-1}+\left(X_{i}^{t}-X_{*}\right)
$$

In the proposed algorithm balance between local and global search has been maintained. Movements of the bats by toggle between local search and global search is controlled by the pulse rate $r$ and receipt or refusal of a new-fangled engendered solution is controlled by loudness $A$.

$$
\begin{aligned}
& r^{t}=\left(\frac{r_{0}-r_{\infty}}{1-t_{\max }}\right)\left(t-t_{\text {max }}\right)+r_{\infty} \\
& A^{t}=\left(\frac{A_{0}-A_{\infty}}{1-t_{\max }}\right)\left(t-t_{\max }\right)+A_{\infty}
\end{aligned}
$$

The pseudocode is:

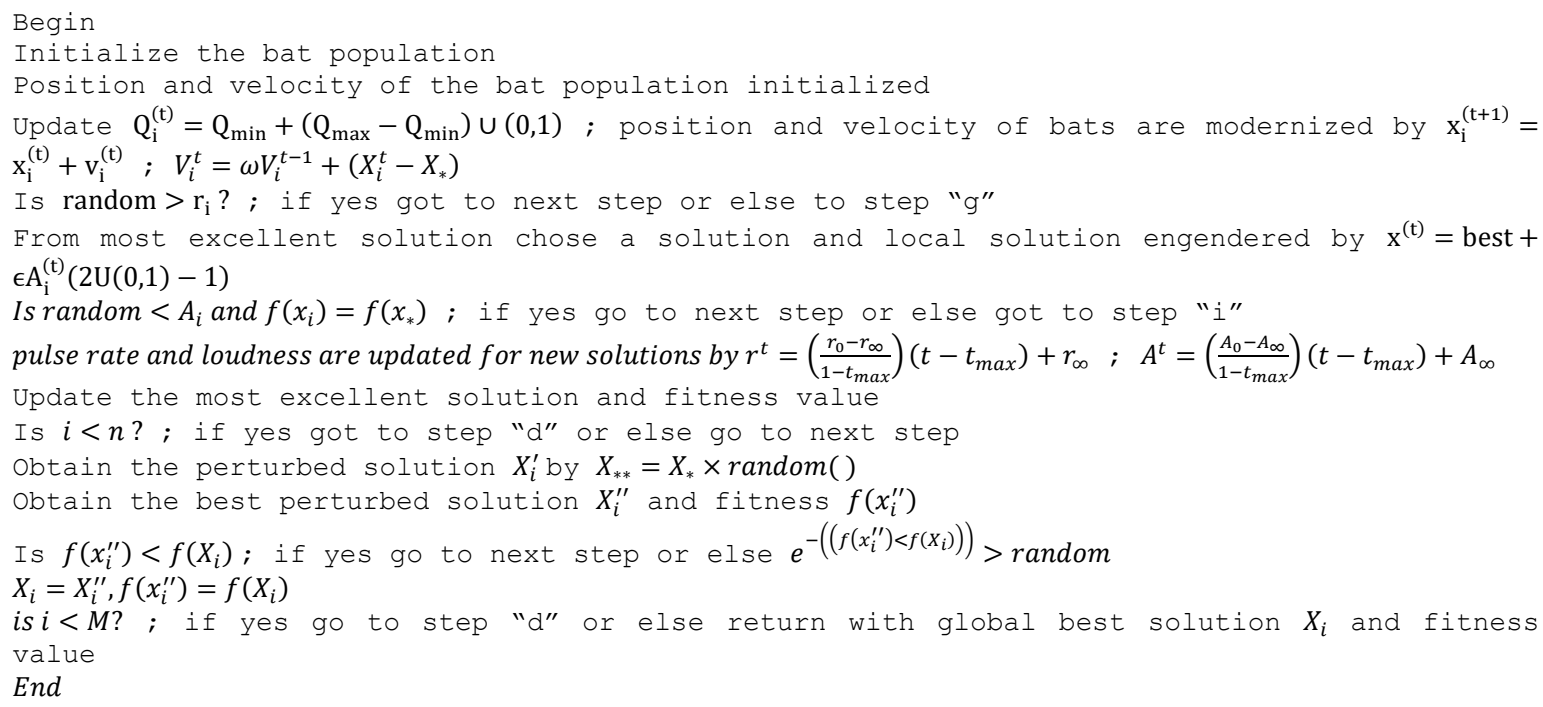




\section{IMPROVED KIDNEY SEARCH ALGORITHM}

Kidney search algorithm imitates assorted progression of a biological kidney. Four main activities: filtration, re-absorption, secretion, and excretion play major role in the operation of kidneys. In initial phase, a random population of probable solutions is created and re-absorption, secretion and excretion are imitated in the search process to check various conditions entrenched to the algorithm. The algorithm is built to improve the search even a potential solution moved to $\mathrm{W}$ and it will be brought back to the FB. GFR test is utilized to verify the fitness of kidneys [18]. The test approximately gives the capacity of blood that pass through the glomeruli every minute. Depend on the GFR test consequence which is less than 15 or falls between 15 and 60 or is more than 60 a particular deed will be executed. This procedure implemented to improve the rate of exploration and finding the optimal solution. The GFR testing procedure is added at the end of every iteration. When GFR level is less than 15, the procedure is repetitive with the population in Filtered Blood. When GFR level is between 15 and 60, a progress of practical solutions in Filtered blood is implemented as a treatment for shortened kidney function. This progression increases the exploration ability and is planned to help the algorithm in discovery of enhanced solution. If the GFR level is larger than 60, then kidney function is common, in which case no extra progression is added to algorithm. Movement equation is (26).

$$
Z_{i+1}=Z_{i}+\operatorname{rand}\left(Z_{\text {best }}-Z_{i}\right)
$$

Filtering of the solutions is done with a filtration rate and Calculation of the filtration rate $\left(l_{r}\right)$ is done using the following (27).

$$
l_{r}=\beta \times \frac{\sum_{i=1}^{S} f\left(y_{i}\right)}{s}
$$

$\beta$ is a constant value between 0 and 1 and is attuned in advance, s represents the size of the population, and $f\left(y_{i}\right)$ represents an objective function of solution y at ith iteration. In every iteration, previous to integration the FB and W will be population for the subsequent iteration. The algorithm computes the GFR level based on the fr in FB.

$$
\text { Glomerular filtration rate } \text { minimum }=120-\left(\frac{f r_{F B} * 100}{f r}\right)
$$

The pseudocode is:

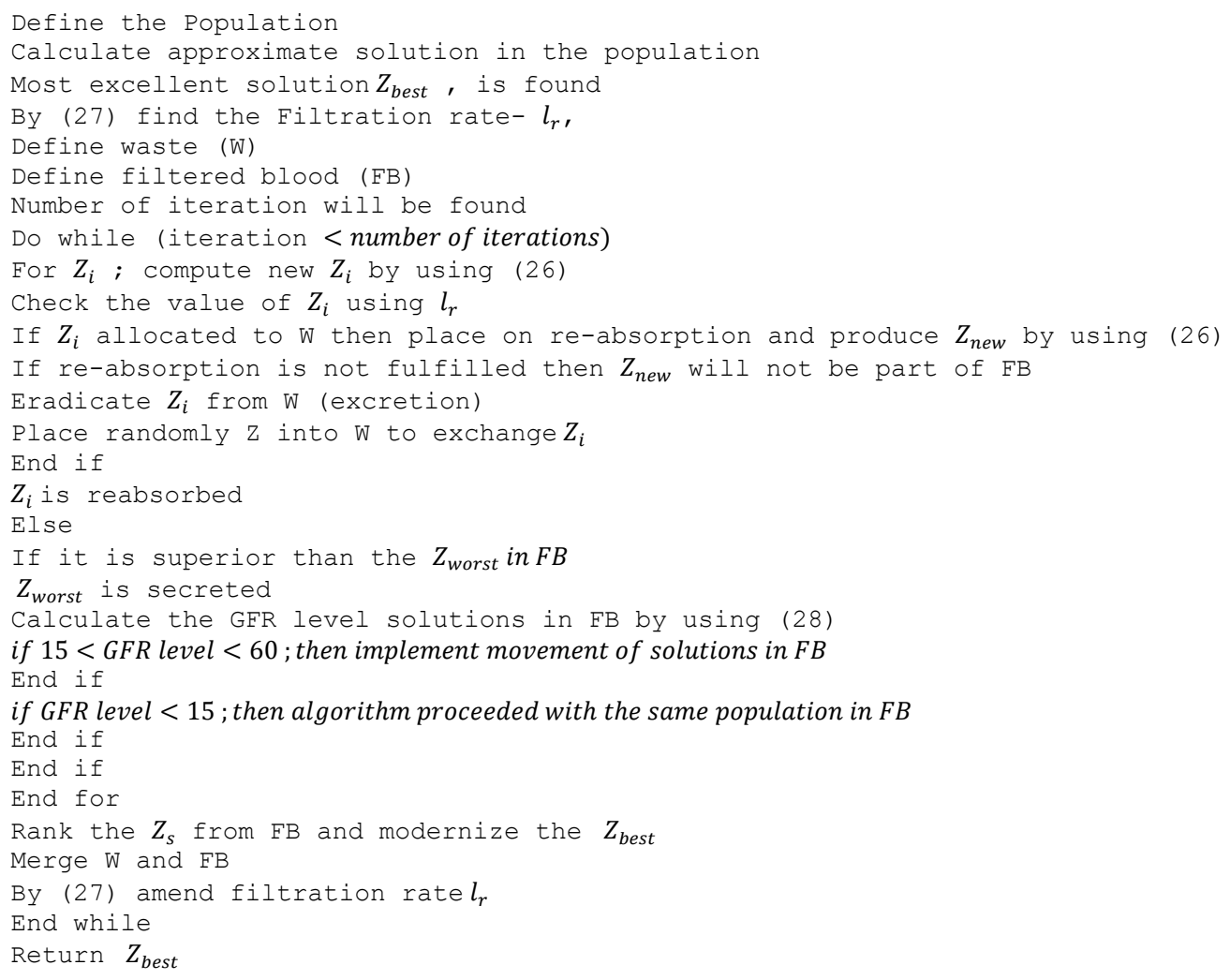

True power loss reduction by mountain zebra, augmented bat and improved kidney ... (Lenin Kanagasabai) 


\section{SIMULATION RESULTS}

At first in standard IEEE 14 bus system, the validity of the proposed MZA, AB and IKS algorithm has been tested. The comparison of results is presented in Table 1.

Table 1. Comparison results

\begin{tabular}{cccccc}
\hline Control variables & ABCO [19] & IABCO [19] & MZA & AB & IKS \\
\hline V1 & 1.06 & 1.05 & 1.00 & 1.05 & 1.01 \\
V2 & 1.03 & 1.05 & 1.01 & 1.04 & 1.00 \\
V3 & 0.98 & 1.03 & 1.00 & 1.02 & 1.05 \\
V6 & 1.05 & 1.05 & 1.04 & 0.90 & 1.06 \\
V8 & 1.00 & 1.04 & 0.92 & 0.109 & 0.91 \\
Q9 & 0.139 & 0.132 & 0.110 & 0.920 & 0.918 \\
T56 & 0.979 & 0.960 & 0.922 & 0.908 & 0.913 \\
T47 & 0.950 & 0.950 & 0.910 & 1.000 & 1.001 \\
T49 & 1.014 & 1.007 & 1.002 & 4.50009 & 4.49971 \\
Ploss (MW) & 5.92892 & 5.50031 & 4.99204 & & \\
\hline
\end{tabular}

Validity of proposed MZA, AB and IKS algorithm has been verified in standard IEEE 118-bus test system. Limitations on reactive power source are listed in Table 2, and Table 3 shows good performance of the proposed algorithms.

Table 2. Reactive power sources limits

\begin{tabular}{cccccccc}
\hline BUS NO & 5 & 34 & 37 & 44 & 45 & 46 & 48 \\
\hline QC MAX & 0.00 & 14.00 & 0.00 & 10.00 & 10.00 & 10.00 & 15.00 \\
QC MIN & -40.00 & 0.00 & -25.00 & 0.00 & 0.00 & 0.00 & 0.00 \\
BUS NO & 74 & 79 & 82 & 83 & 105 & 107 & 110 \\
QC MAX & 12.00 & 20.00 & 20.00 & 10.00 & 20.00 & 6.00 & 6.00 \\
QC MIN & 0.00 & 0.00 & 0.00 & 0.00 & 0.00 & 0.00 & 0.00 \\
\hline
\end{tabular}

Then IEEE 300-bus system [21] is used as test system to validate the performance of the proposed MZA, AB and IKS algorithm. Table 4 shows the comparison of real power loss obtained after optimization. Real power loss has been considerably reduced when compared to the other standard reported algorithms. Compared to EEA method, proposed IKS algorithm reduces $4.77 \%$ real power loss.

Table 3. Real power loss comparison results

\begin{tabular}{ccccccc}
\hline Active power loss (p.u) & $\begin{array}{c}\text { Method- BBO } \\
{[20]}\end{array}$ & $\begin{array}{c}\text { Method- ILSBBO/ } \\
\text { Strategy I [20] }\end{array}$ & $\begin{array}{c}\text { Method -ILSBBO/ } \\
\text { Strategy II [20] }\end{array}$ & MZA & AB & IKS \\
\hline Minimum value & 128.7700 & 126.9800 & 124.7800 & 118.7920 & 116.9900 & 116.0405 \\
Maximumvalue & 132.640 & 137.3400 & 132.3900 & 123.8430 & 123.4127 & 122.7196 \\
Average value & 130.2100 & 130.3700 & 129.2200 & 120.1249 & 119.7901 & 119.0012 \\
\hline
\end{tabular}

Table 4. Comparison of real power loss

\begin{tabular}{ccccccc}
\hline Parameter & EEA Method [22] & EGA Method [22] & CSA Method [23] & MZA & AB & IKS \\
\hline PLOSS (MW) & 650.6027 & 646.2998 & 635.8942 & 620.1982 & 620.1041 & 619.5427 \\
\hline
\end{tabular}

\section{CONCLUSION}

In this paper, optimal reactive power problem has been successfully solved by MZA, augmented AB and IKS algorithm. Proposed MZA utilizes its special logical, cooperative and self-determining approach in the search of a best path to arrive at grassland. This confers it to reach optimum results faster than some other searching agents. In the proposed $\mathrm{AB}$ algorithm, balance between local and global search has been maintained. Movements of the bats by toggle between local search and global search is controlled by the pulse rate $r$ and receipt or refusal of a new-fangled engendered solution is controlled by loudness A. IKS algorithm has been built to advance the search, even a potential solution moved to $\mathrm{W}$ and it will be brought back to the FB. GFR test is utilized to verify the fitness of kidneys. The test approximately gives the capacity of blood that pass through the glomeruli every minute. Proposed MZA, AB and IKS algorithms have 
performed well when evaluated in standard IEEE 14-bus, 118-bus, and 300-bus test systems. True power loss reduced considerably when compared to other standard algorithms.

\section{REFERENCES}

[1] K. Y. Lee, Y. M. Park, and J. L. Ortiz, "Fuel-cost minimisation for both real and reactive-power dispatches," Proceedings Generation, Transmission and Distribution Conference, vol. 131, no. 3, pp. 85-93, 1984.

[2] N. I. Deeb and S. M. Shahidehpour, "An efficient technique for reactive power dispatch using a revised linear programming approach,” Electric Power System Research, vol. 15, no. 2, pp. 121-134, 1988.

[3] M. R. Bjelogrlic, M. S. Calovic, P. Ristanovic and B. S. Babic, "Application of Newton's optimal power flow in voltage/reactive power control," IEEE Trans Power System, vol. 5, no. 4, pp. 1447-1454, 1990.

[4] S. Granville, "Optimal reactive dispatch through interior point methods," IEEE Transactions on Power System, vol. 9, no. 1, pp. 136-146, 1994.

[5] N. Grudinin, "Reactive power optimization using successive quadratic programming method," IEEE Transactions on Power System, vol. 13, no. 4, pp. 1219-1225, 1998.

[6] W. Yan, J. Yu, D. C. Yu and K. Bhattarai, "A new optimal reactive power flow model in rectangular form and its solution by predictor corrector primal dual interior point method," IEEE Transactions on power systems, vol. 21, no. 1, pp.61-67, 2006.

[7] A. Mukherjee and V. Mukherjee, "Solution of optimal reactive power dispatch by chaotic krill herd algorithm," IET Generation, Transmission and Distribution, vol. 9, no. 15, pp. 2351-2362, 2015.

[8] M. A/P Morgan, N. R. H. Abdullah, M. H. Sulaiman, M. Mustafa and R. Samad, "Computational intelligence technique for static VAR compensator (SVC) installation considering multi-contingencies (N-m)," ARPN Journal of Engineering and Applied Sciences, vol. 10, no. 22, pp. 17059-17064, 2015.

[9] M. H. Sulaiman, Z. Mustaffa, H. Daniyal, M. R. Mohamed and O. Aliman, "Solving optimal reactive power planning problem utilizing nature inspired computing techniques," ARPN Journal of Engineering and Applied Sciences, vol. 10, no. 21, pp. 9779-9785, 2015.

[10] M. H. Sulaiman, W. L. Ing, Z. Mustaffa and M. R. Mohamed, "Grey wolf optimizer for solving economic dispatch problem with valve-loading effects," ARPN Journal of Engineering and Applied Sciences, vol. 10, no. 21, pp. 9796-9801, 2015.

[11] K. Pandiarajan, and C. K. Babulal, "Fuzzy harmony search algorithm based optimal power flow for power system security enhancement," International Journal of Electrical Power and Energy Systems, vol. 78, pp. 72-79. 2016.

[12] M. H. Sulaiman, Z. Mustaffa, M. R. Mohamed and O. Aliman, "An application of multi-verse optimizer for optimal reactive power dispatch problems," International Journal of Simulation: Systems, Science and Technology, vol. 17, no. 41, pp. 5.1-5.5. 2017.

[13] M. A/P Morgan, N. R. H. Abdullah, M. H. Sulaiman, M. Mustafa and R. Samad, "Multi-objective evolutionary programming (MOEP) using mutation based on adaptive mutation operator (AMO) applied for optimal reactive power dispatch," ARPN Journal of Engineering and Applied Sciences, vol. 11, no. 14, pp. 8884-8888, 2016.

[14] R. Ng Shin Mei, M. H. Sulaiman, Z. Mustaffa, "Ant lion optimizer for optimal reactive power dispatch solution," Journal of Electrical Systems, "Special Issue AMPE2015", pp. 68-74, 2016.

[15] M. Morgan, N. R. H. Abdullah, M. H. Sulaiman, M. Mustafa, R. Samad, "Benchmark studies on optimal reactive power dispatch (ORPD) based multi-objective evolutionary programming (MOEP) using mutation based on adaptive mutation adapter (AMO) and polynomial mutation operator (PMO)," Journal of Electrical Systems, vol. 12, no. 1, pp. 121-132, 2016.

[16] R. Ng Shin Mei, M. H. Sulaiman, Z. Mustaffa, H. Daniyal, "Optimal reactive power dispatch solution by loss minimization using moth-flame optimization technique," Applied Soft Computing, vol. 59, pp. 210-222, 2017.

[17] X.S. Yang, "Bat algorithm for multi-objective optimization," International Journal of Bio-Inspired Computation, vol. 3, no. 5, 267- 274, 2011 .

[18] N. S. Jaddi, J. Alvankarian, and S. Abdullah, "Kidney-inspired algorithm for optimization problems," Communications in Nonlinear Science and Numerical Simulation, vol. 42, pp. 358-369, 2017.

[19] C. M. K. Sivalingam, S. Ramachandran and P. S. S. Rajamani, "Reactive power optimization in a power system network through metaheuristic algorithms," Turkish Journal of Electrical Engineering and Computer Science, vol. 25, no. 6, pp. 4615 - 4623, 2017. Doi: 10.3906/elk-1703-159.

[20] Jiangtao Cao, Fuli Wang and Ping Li, "An improved biogeography-based optimization algorithm for optimal reactive power flow," International Journal of Control and Automation, vol. 7, no. 3, pp.161-176, 2014.I

[21] IEEE, "The IEEE-test systems," 1993, [Online]. Available: https://electricgrids.engr.tamu.edu/electric-grid-testcases/ieee-300-bus-system/.

[22] S. S. Reddy, "Optimal reactive power scheduling using cuckoo search algorithm," International Journal of Electrical and Computer Engineering, vol. 7, no. 5, pp. 2349-2356, 2017.

[23] S.S. Reddy, P. R. Bijwe and A. R. Abhyankar, "Faster evolutionary algorithm based optimal power flow using incremental variables," Electrical Power and Energy Systems, vol. 54, pp. 198-210, 2014. 